syndrome was well three and a half years after termination of dialysis with a serum creatinine concentration of $156 \mu \mathrm{mol} / 1(1.8 \mathrm{mg} / 100 \mathrm{ml})$.

Three patients had received cadaveric renal transplants and conventional immunosuppressive treatment. Two had accelerated hypertension and one crescentic glomerulonephritis. Radionuclide studies in the immediate postoperative period confirmed that the transplants were functioning in all cases. Further studies using ${ }^{99 \mathrm{~m}} \mathrm{Tc}$ labelled diethylenetriamine penta-acetic acid (DTPA) 22, 72, and 278 weeks later respectively proved that each of the three grafts had stopped functioning and that the patients' own kidneys were functioning (figure). This finding was not anticipated in any of these patients when the scan was arranged. The two patients with accelerated hypertension had remissions lasting 64 and 74 weeks before they again became uraemic. The third patient remained well with a plasma creatinine concentration of $77 \mu \mathrm{mol} / 1(0.9 \mathrm{mg} / 100 \mathrm{ml})$ two and a half years after the discovery that her transplant was not functioning.

Immunosuppressive treatment was withdrawn in the two patients given transplants for accelerated hypertension when recovery of their own renal function was detected. The two patients with mesangiocapillary glomerulonephritis were given immunosuppressive treatment when renal function fell again after the original recovery, but no benefit resulted. The patient with Goodpasture's syndrome had been treated by plasmapheresis in the months before dialysis, and immunosuppressive treatment was restarted when recovery occurred. Of the two patients with crescentic glomerulonephritis, one given a renal transplant continued immunosuppressive treatment, and one treated by regular haemodialysis received immunosuppressive treatment again when recovery occurred.

\section{Discussion}

The high incidence of recovery of renal function in our series $(2.8 \%)$ suggests that recovery may occur more frequently than is recognised. Unnecessary dialysis is clearly undesirable. Recovery of renal function is relatively easy to detect in patients treated by dialysis. In the presence of a renal transplant evidence of recovery of function of the patient's own kidneys by radionuclide imaging has not previously been described. We emphasise that neither recovery of host renal function nor loss of graft function had been detected before the scans were performed.

Our three patients with transplants whose own kidneys recovered function amounted to about $5 \%$ of our patients alive with functioning grafts more than one year after operation. Similar experience in other centres would make it necessary to question the validity of long term transplant survival statistics. There may be a place for routine renal scanning of all patients with kidney grafts after perhaps one and two years, even when overall renal function is satisfactory. The possibility of recovery of function, albeit remote, must also be considered whenever a patient begins renal replacement treatment and particularly if bilateral nephrectomy is contemplated.

Whether immunosuppressive treatment should be continued or reinstituted after recovery of host kidney function depends on the primary renal disease. We stopped immunosuppressive treatment in those patients with accelerated hypertension, but continued it in patients with primary, glomerulonephritis.

\section{References}

${ }^{1}$ Kopsa H, Schmidt P, Zazgornik J, Pils P, Balke P. Recovery of renal function following prolonged acute renal failure. Proc Eur Dial Transplant Assoc 1979;15:495-9.

2 Brynger H, Brunner FP, Chantler C, et al. Combined report on regular dialysis and transplantation in Europe. X, 1979. Proc Eur Dial Transplant Assoc 1981;17:2-86.

\title{
Attempted suicide by insulin injection treated with artificial pancreas
}

\author{
H GIN， B LARNAUDIE, J AUBERTIN
}

\begin{abstract}
An elderly woman with longstanding insulin dependent diabetes tried to commit suicide by injecting 400 units of insulin subcutaneously (usual total daily dose 56 units). She was admitted to hospital within the hour and treated with the aid of an artificial pancreas. This avoided the usual difficulty of the physician having to cope with rapid and substantial fluctuations in blood glucose concentrations and 67 hours after the overdose insulin was reinstituted.

Using an artificial pancreas in insulin overdose is an important advance in management and may avoid the need for surgical intervention such as excising the site of injection.
\end{abstract}

\footnotetext{
Clinique Médicale et des Maladies infectieuses, Hôpital Pellegrin, 33076 Bordeaux Cedex, France

H GIN, MD, lecturer in internal medicine

B LARNAUDIE, MD, lecturer in internal medicine

J AUBERTIN, MD, professor of internal medicine and infectious diseases

Correspondence to: Dr H Gin.
}

\section{Introduction}

Attempted suicide by injection of insulin is rare, even in diabetics. ${ }^{1}$ In all cases, however, hypoglycaemic coma ensues which may be followed by death, hypoglycaemic encephalopathy, or recovery, depending on how soon normoglycaemia is restored. Treatment consists in rousing the patient by means of glucagon injection or glucose injection or both, then keeping him awake and alert by maintaining an adequate intake and avoiding both an overload of glucose and insulin deficiency. Finally, usual insulin treatment is resumed.

Though with close medical supervision such treatment is perfectly practicable, it is often complicated by rapid and substantial changes in the blood glucose concentration. An artificial pancreas, however, provides continuous blood glucose analysis and automatically modulates glucose perfusion. Using this device allows insulin to be resumed as soon as necessary and may avoid the need for such measures as excising the site of injection. ${ }^{2}$

\section{Case history}

A 70 year old woman had a history of insulin dependent diabetes since the age of 18, for which she was receiving a total of 56 units of 
Rapitard insulin (Novo) daily. For several days she had had a painful anal fissure, which she suddenly found so intolerable that at $5 \mathrm{pm}$ she attempted suicide by injecting 400 units of insulin subcutaneously. She immediately alerted members of the household, and the doctor was called. He gave her $50 \mathrm{~g}$ carbohydrate as sugar lumps and 45 minutes later she was admitted to hospital.

On arrival she was comatose and hyperreflexive and her venous glucose concentration was $1 \mathrm{mmol} / 1(18 \mathrm{mg} / 100 \mathrm{ml})$. Hypertonic glucose solution was administered and an artificial pancreas (Biostator GCIIS, Miles Laboratories) prepared, initially programmed for zero insulin output and to yield a blood glucose concentration of 4.4$5.0 \mathrm{mmol} / \mathrm{l}$. The patient's requirement for glucose rapidly exceeded the capability of the artificial pancreas and an auxiliary pump was set up in conjunction with the machine and directly under its control. This raised the maximum glucose supply available to $500 \mathrm{mg} / \mathrm{min}$ using a glucose solution of $1110 \mathrm{mmol} / \mathrm{l}(20 \mathrm{~g} / 100 \mathrm{ml})$, which avoided the risk of phlebitis and large volumes infused $(150 \mathrm{ml} /$ hour maximum $)$.

Her level of consciousness was soon satisfactory and remained so. The blood glucose concentration continued to be stable, though a large glucose intake was required for more than 48 hours with no need of insulin, despite a return to normal meals (see figure). She first needed insulin at 67 hours, her requirement initially remaining low. The artificial pancreas was discontinued at 84 hours.

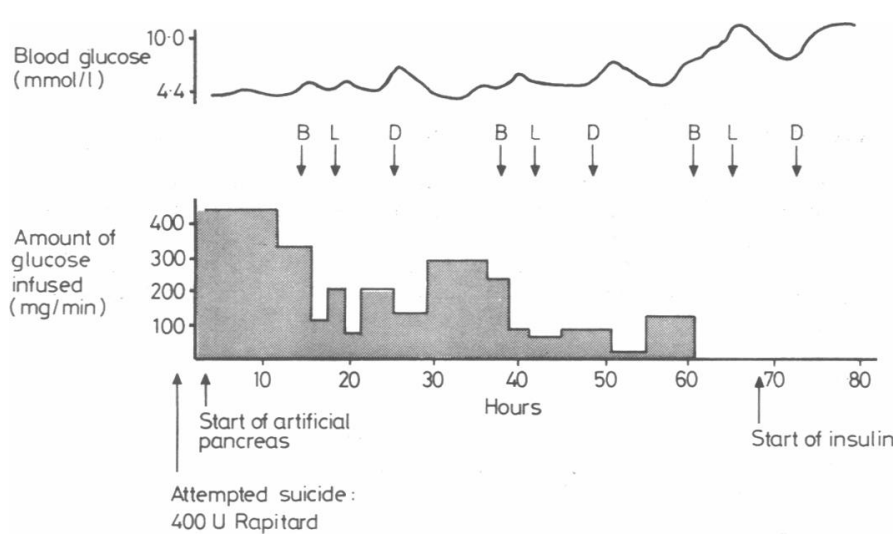

Blood glucose concentrations and amounts of glucose infused by artificial pancreas during first 80 hours after attempted suicide. $B=$ Breakfast $(70 \mathrm{~g}$ carbohydrate). $\mathrm{L}=\mathrm{Lunch}$ (80 g carbohydrate). $\mathrm{D}=$ Dinner (80 g carbohydrate).

Conversion: SI to traditional units-Blood glucose: $1 \mathrm{mmol} / 1 \approx 18 \mathrm{mg} / 100$ $\mathrm{ml}$.

The total amount of glucose administered intravenously was $586 \mathrm{~g}$, and during the same period oral carbohydrate intake was $700 \mathrm{~g}$. This intake was adjusted to her needs without variations in the glucose concentration and without the need for insulin. Subsequently she was gradually returned to her usual insulin dosage. A pancreatic stimulation test by intravenous injection of $1 \mathrm{mg}$ glucagon and quantitative analysis of $\mathrm{C}$ peptide confirmed virtually non-existent residual pancreatic function. Appropriate treatment cleared the initial painful condition and the patient returned home.

\section{Discussion}

This case illustrates the importance of the amount of glucose infused and particularly the duration of the need for glucose, which considerably exceeded the duration of the activity of Rapitard types of insulin injected subcutaneously. This difference may be explained by the need to replenish exhausted glycogenic reserves or possibly by progressive release of free insulin by insulin antibodies saturated by the initial insulin load. In our patient we did not measure free insulin concentrations or test for insulin antibodies and we did not estimate glycogenic reserves. Whatever the explanation, the phenomenon is well known ${ }^{3}$ but has never been determined quantitatively. Without continuous recording of glucose concentrations it is difficult to judge adequately the required oral and venous intake. It is also difficult to decide when to resume insulin treatment and so avoid repeated hypoglycaemic episodes. It is the duration of hypo- glycaemia or of successive hypoglycaemic periods which causes posthypoglycaemic encephalopathy, rather than the quantity of insulin injected. The stated amount of glucose required varies from one investigator to another, ranging from $500 \mathrm{~g}^{4}$ to $1800 \mathrm{~g}^{3}{ }^{3}$ In all cases and in the judgment of all investigators massive intake was necessary. Nevertheless, it was never possible to measure the intake precisely.

The effect of using an artificial pancreas to treat an insulin overdose may be compared to that of its use in the diagnosis and surgical removal of an insulinoma. ${ }^{5}$ In insulinoma the glucose is administered for only a few hours a day, and a few hours after surgery normal glycaemic concentrations are maintained spontaneously. The metabolic conditions are therefore completely different from that after a suicide attempt with a large amount of insulin, since, though secretory hyperinsulinism exists, the metabolic consequences disappear as soon as it is suppressed.

\section{References}

${ }^{1}$ Bourgeois M, Aubertin J, Favarel-Garrigues JC, Orgogozo JM. Les suicides insuliniques: aspects médicaux et psychiatriques à propos de deux observations. Bordeaux Médical 1978;11:835-9.

${ }^{2}$ Campbell IN. Suicidal insulin overdose managed by excision of insulin injection site. $\mathrm{Br} \mathrm{Med} \mathcal{F} 1982 ; 285: 408-9$.

3 Tourniaire J, Guinet P, Sassolas G, Chalier M. Suicides et tentatives de suicide par l'insuline. Revue Lyonnaise de Médecine 1970;19:49-58.

4 Lindgren L. Enormous dose of insulin. Acta Med Scand 1960;163:297300.

5 Trovati M, Pagano G, Cartia Q, et al. Dextrose infusion by artificial pancreas in diagnosis of insulinoma. Lancet 1982; ; 631-2.

(Accepted 26 April 1983)

ONE HUNDRED YEARS AGO On Saturday last, December 15th, Miss Chreiman gave a demonstration in the Vestry Hall, Hampstead, of her system of "gymnastic exercises" for young girls. Although the application of the term is quite correct, the word "gymnastic" will probably convey to most readers an erroneous idea of the nature of the exercises taught. They are intended, we are told, to develop the strength of every part of the body; to correct defects of carriage ; to provide regulated and enjoyable exercise ; and therefore, as a consequence, to impart flexibility and grace in movement and attitude, and a healthier growth of the body. The exercises are executed at the word of command, rhythmically, to music. There are exercises for the muscles moving the fingers, the wrists, the arms and for the trunk. Light wooden dumb-bells are used in these exercises; and, in other exercises, long so-called bar-bells, about four feet in length, are carried by the pupils, who go through a variety of manoeuvres with these instruments. For other exercises, light Indian clubs are employed. On the occasion to which we refer, the performance concluded by the execution of a number of evolutions of the most complicated and various kinds, reminding the spectator alternately of the manoeuvres of a squad of volunteers and of a country dance. The young pupils went through the exercises with wonderful steadiness, and with evident enjoyment. We have no doubt that the system elaborated by Miss Chreiman is of great use in developing the muscular and respiratory systems of growing children; and not only so, but in encouraging a grace of pose and movement which the art of the costumière can never impart. We were forcibly reminded of the well-known words of Pope, as we watched the evolutions of the class. "True ease," he says,

"Comes from art, not chance,

As those move easiest who have learnt to dance." In the days of Queen Anne, dancing was perhaps the nearest obtainable approach to "scientific gymnastic exercises." Dancing then did not consist in turning round on the tips of the toes a greater or less number of times in the minute, but was an exercise for the public performance of which much serious and private practice of complex manoeuvres and attitudes, calling into play a great variety of muscles, was necessary. (British Medical fournal, 1883;ii:1253.) 